\title{
EL TRATO DISCRIMINATORIO \\ DE LA FILIACIÓN EXTRAMATRIMONIAL EN MARRUECOS
}

\author{
ABDELHAMID ADNANE
}


SUMARIO

1. INTRODUCCIÓN. 2. LA MUDAWANA APRECIADA DESDE SUS ORÍGENES. 3. REGULACIÓN DE LA FILIACIÓN. 4. DE LOS DERECHOS DE LOS HIJOS. 5. DE LA PATERNIDAD. 6. DE LA PRUEBA DE ADN, DE LA FILIACIÓN, ADOPCIÓN E IMPEDIMENTOS DEL MATRIMONIO. 7. REFLEXIONES FINALES. 


\title{
EL TRATO DISCRIMINATORIO DE LA FILIACIÓN EXTRAMATRIMONIAL EN MARRUECOS
}

\author{
ABDELHAMID ADNANE \\ Profesor de Derecho Constitucional \\ Universidad Pablo de Olavide de Sevilla
}

\section{INTRODUCCIÓN}

La proclamación del principio de igualdad, junto con la garantía de ciertos derechos fundamentales, ha sido una constante en todos los textos constitucionales en Marruecos ${ }^{1}$. Sin embargo, una de las críticas dirigidas a esta norma fundamental apunta su bajo tenor normativo por razón de la inadecuación del control apriorístico, en su virtud establecido, para salvaguardar su supremacía. De ahí que normas con rango de ley contrarias a sus disposiciones hayan podido desplegar su virtualidad en el ordenamiento jurídico atentando claramente contra la unidad del mismo.

Con la última reforma del texto constitucional, aprobada por referéndum del 1 de julio de $2011^{2}$, se introdujo la llamada «excepción de inconstitucionalidad $»^{3}$ que permite un control a posteriori de la disposiciones legales, permitiendo de este modo fortalecer la normatividad de todas las disposiciones constitucionales.

${ }^{1}$ La primera es de 1962, la segunda de 1970, la tercera de 1972, la cuarta de 1992, la penúltima de 1996 y la actual es la de 2011.

2 Promulgada por dahir n. ${ }^{\circ} 1.11 .91$, de 29 de julio de 2011.

3 Vid. artículo 133 de la Constitución marroquí de 2011. 
El objeto de este trabajo es demostrar la incompatibilidad de ciertas disposiciones del Código de Familia de Marruecos con la norma fundamental, por cuanto rompen el principio de igualdad sin justificación objetiva ni razonable y, por ende, producen una situación de desamparo en la que se ve obligada a vivir una categoría social inerme: los hijos nacidos fuera del matrimonio.

La reflexión llevada a cabo al respecto en estas páginas, debido a la naturaleza peculiar del tema, pasa, en primer lugar, por precisar el posible origen histórico de ciertas disposiciones del citado código. A continuación se hará un repaso crítico tanto a la distinción, que en su seno se da, entre hijos legítimos e ilegítimos como a la consiguiente cuestión de reconocimiento de la paternidad y de los derechos que de ello derivan. Por último, se abordará la problemática que plantea el recurso a la prueba de $\mathrm{ADN}$ en asuntos de filiación, para terminar con una relectura sistemática de las dos instituciones: filiación y Kafala ${ }^{4}$.

\section{LA MUDAWANA APRECIADA DESDE SUS ORÍGENES}

La primera codificación del derecho de familia en Marruecos se remonta a 1958 y fue el resultado de una doble influencia. Por una parte, la inspiración en el derecho musulmán, y, por otra y de modo indirecto, el derecho francés cuya instauración se vio favorecida por el protectorado.

Esta filiación parcialmente francesa de la legislación marroquí sobre la institución de la familia le hace al legislador marroquí merecedor de parte de las críticas dirigidas por SALVIOLI al Código Civil francés ${ }^{5}$ cuyas bases, igual que

\footnotetext{
${ }^{4}$ A tenor del artículo 149 del Código de familia marroquí:

«La adopción (Attabani) es nula jurídicamente y no produce ninguno de los efectos de la filiación parental legítima.

La adopción de gratificación (Jaza) o de asimilación al rango de hijo (Tanzil), en virtud de la cual una persona se coloca en el rango del primer heredero, no estable la filiación y se regirá por la normativa reguladora del testamento (Wasiya).» Ley 15-01 promulgada por dahir el 13 de junio de 2002 (B.O. n. ${ }^{\circ}$ 5036, de 15 septiembre 2002).

5 «Si según el derecho francés estaba prohibida la investigación de la paternidad ilegítima, o en otros términos, ni la madre ni el niño pueden producir una pretensión de esta naturaleza frente al padre, la madre puede exponer el hijo ilegítimo, sin responsabilidad alguna, en un Hospicio, para que sea sostenido por la beneficencia pública. No puede llevarse más allá la parcialidad y unilateralidad a favor de las clases ricas: se ponen a cargo del Estado o de las corporaciones públicas, los gastos del libertinaje de las personas ricas. Se trataba de proteger los intereses de la propiedad y de la familia de los ricos frente a los pobres». Cfr. Anton MENGUER. «El Derecho Civil y los Pobres». Versión española realizada por Adolfo POSADA. Granada, Ed. Comares, S.L., 1998, pág. 189.
} 
su imitador, el alemán ${ }^{6}$, descansan, en contra de los principios revolucionarios ${ }^{7}$ proclamados e incluso puestos en práctica durante un breve lapso de tiempo, sobre un derecho consuetudinario que es, en substancia, el resultado de una lucha de intereses, con éxito favorable a los poderosos y, por lo tanto en detrimento de los débiles como categoría general que cuenta en su seno de un grupo especialmente vulnerable, los hijos adulterinos. Éstos se ven claramente perjudicados ya que sus intereses no encuentran expresión legal mediante una regla jurídica, por no tener ni voz ni portavoz y, de ahí, carecer del poder y de la influencia suficiente para inducir a que los demás los reconocieran. Ello indujo a SALVIOLI ${ }^{8}$ a afirmar que «la inferioridad de los hijos ilegítimos y especialmente la prohibición de la investigación de la paternidad no representan más que medidas legales encaminadas a defender los intereses de la clase rica, en perjuicio de la otra», concluyendo que «al abolir el antiguo principio de que el hijo ilegítimo? podía por cualquier medio buscar su propio padre y que la madre podía obligar al seductor a mantenerla, fue inducido por el pretexto de defender la familia y la herencia, e impedir escándalos entre las familias ricas en cuyo seno tienen los hijos ilegítimos interés material en entrar para encontrar no tanto un nombre como los bienes», por lo que esta medida no es más que un expediente para asegurar una impunidad injusta e inmoral, en daño de estos desheredados.

Sin embargo, y es justo dejar constancia de ello, el derecho francés en materia de Derecho de Familia distinguía hasta fechas recientes entre hijos legítimos e hijos adulterinos, careciendo estos últimos de los derechos reconocidos a los primeros nacidos en un marco familiar, como era el caso de la ley del 2001 que, a pesar de haber afirmado el principio de igualdad en materia de sucesiones,

${ }^{6}$ Cfr. Anton MENGUER. «El Derecho Civil y los Pobres». Op. cit. págs. 122-123.

${ }^{7}$ La legislación revolucionaria no sólo mantuvo íntegro el derecho a los alimentos frente al padre ilegítimo sino que la Convención, en su sesión del 4 de junio de 1793, votó el principio de que los hijos ilegítimos debían gozar de un derecho hereditario sobre los bienes del padre y de su madre. Pocos meses después, la ley del 12 de Brumario II (2 de noviembre 1793) establecía que los hijos ilegítimos tienen los mismos derechos hereditarios legales, sobre los bienes del padre o de la madre, que los hijos legítimos; y en aquella misma ley se reconocía un recíproco derecho hereditario ab intestato entre el hijo ilegítimo y los parientes colaterales por la línea materna o paterna, en cuanto el causante no dejase herederos en línea ascendente o descendente. En virtud de esta ley los hijos legítimos y los ilegítimos venían casi a quedar equiparados, en sus más esenciales relaciones. La Convención iba por tal camino demasiado lejos, y por virtud de su misma exageración, determinó la reacción contraria ocurrida más tarde. Cfr. Anton MENGUER. «El Derecho Civil y los Pobres». Op. cit., pág. 190.

${ }^{8}$ Cf. GIUSEPPE SALVIOLI. «El Derecho Civil y El Proletariado». Estudio preliminar y edición de B. Clavero. Ed. Secretariado de Publicaciones de la Universidad de Sevilla, 1979, pág. 93.

9 Estimamos conveniente dejar claro que una persona nunca puede ser ilegítimo. Ilegítimo sería el modo de su concepción, pero la ilegitimidad jamás puede alcanzar a una persona. 
mantenía la distinción entre los hijos legítimos y los naturales. Pero, finalmente, con la ordenanza del año 2005 se reconocen los derechos de los hijos con independencia de la situación de los progenitores, por lo que desapareció la noción de hijo adulterino del Código civil francés ${ }^{10}$.

En cuanto al legislador marroquí, a pesar de las adaptaciones introducidas por la última reforma acontecida en 2004 y que se anotan en su haber, mantiene esta distinción entre hijos legítimos e ilegítimos desvinculándose, de este modo, de la evolución del Código napoleónico y aplicando una interpretación peculiar de la referencia religiosa como demostraremos a continuación.

En el marco jurídico de la familia en Marruecos, marcado principalmente por el ius religionis, coexisten varias regulaciones de la familia, como la establecida para musulmanes basada principalmente en el Derecho Islámico y, en parte, como queda anunciado, por construcciones jurídicas heredadas de la cultura jurídica francesa, y el aplicado para los judíos, con base en el Derecho Hebraico. Además existe una normativa adaptada para los extranjeros residentes en el país que profesen una religión distinta de la musulmana y de la judía regulada por el Dahir ${ }^{11}$ de 12 de agosto de 1913.

\section{REGULACIÓN DE LA FILIACIÓN}

En el ordenamiento marroquí no existe la denominación de la filiación como matrimonial, sino sólo de legítima. Las vías establecidas en el Código de familia marroquí (en adelante $\mathrm{CF}$ ) para acceder a la legitimidad del hijo son las recogidas en el artículo 152 del $\mathrm{CF}^{12}$. Dicha legitimidad alcanza a los nacidos de

${ }^{10}$ Las reformas del derecho francés en materia de familia han sido aprobadas en el orden que sigue:

En 1938 se suprime la incapacidad jurídica de la mujer casada. En 1941 se establece la posibilidad del divorcio tras tres años de matrimonio. En 1965 se prescinde de la autorización marital para ejercer una actividad profesional. En 1970, en virtud del principio de igualdad, el padre deja de ser el único jefe de la familia. En 1975 se instaura el divorcio consensual. En 1985, se establece la igualdad de los esposos en la gestión de los bienes de la familia y de los hijos. En 1993 se afirma el principio del ejercicio conjunto de la autoridad parental respecto de los hijos con independencia de la situación de los padres. En 2001 se reconoce el permiso de paternidad. En 2005 se reconoce al niño el derecho de recibir el apellido de la familia del padre, de la madre o de ambos a la vez. http://www.culturesfrance.com/adpf-publi/folio/code_civil/205.html.

${ }_{11}$ Dahir es la forma jurídica a través de la cual el monarca ejercía la facultad legislativa.

12 Dispone el artículo 152 del Código de familia marroquí que: «La filiación paterna deriva:

1. de relaciones conyugales (Al Firach);

2. del reconocimiento paterno (Iqrar);

3. de las relaciones sexuales mantenidas por error (Choubha).» 
relaciones conyugales de los progenitores (presunción $A l$ frach $^{13}$ ), de relaciones sexuales por error o duda (subha) y a los beneficiados por el reconocimiento voluntario de la paternidad (istilhak). Además, el artículo 156 del CF contempla la posibilidad de legitimar al hijo engendrado en las relaciones de noviazgo formal, al igual que la concesión realizada por el legislador para beneficiar a los hijos concebidos en relaciones prematrimoniales regularizadas a posteriori en virtud del artículo 16 del $\mathrm{CF}^{14}$.

Veamos, a continuación, cada una de estas vías que aseguran la legitimidad de la filiación.

\section{a) La filiación al firach}

Se regula en el artículo $154 \mathrm{CF}$, donde se precisa que la paternidad (Nasab) resulta automáticamente establecida por los vínculos conyugales si, en primer lugar, el concebido nace a los seis meses de la celebración del matrimonio y la consumación de la relación conyugal ha sido posible, con independencia del vicio de anulabilidad del que pueda adolecer el acto matrimonial, y, en segundo lugar si el hijo nace durante el año posterior a la disolución del matrimonio.

El hijo nacido fuera del matrimonio tendrá la consideración de hijo adulterino, al que se priva de un haz de derechos tal como comprobaremos más adelante.

Muchos países islámicos adaptaron el principio de presunción de paternidad con el fin de atribuir legitimidad a la relación filial entre el niño, nacido en el plazo mínimo legal del embarazo, y el padre siempre y cuando el parto tuviera lugar dentro del matrimonio. En este sentido, las reformas emprendidas en

13 Al firach significa la cama o lecho. Tiene su origen en un relato del profeta a cuyo tenor el hijo se atribuye al firach o al lecho.

${ }^{14}$ A tenor del artículo 16: «El acta matrimonial se considera el medio aceptado de prueba del matrimonio.

Cuando razones de fuerza mayor impiden registrar el acta de matrimonio en su debido tiempo, el tribunal utilizará todos los medios de prueba, para reconocer su existencia, así como el peritaje.

El Tribunal tomará en consideración, durante el proceso de reconocimiento del matrimonio, la existencia de hijos o el embarazo resultante de la relación conyugal y que la acción ha sido iniciada en vida de los dos esposos.

La acción de reconocimiento del matrimonio será admitida a trámite durante un periodo transitorio no superior a cinco años, a contar desde la entrada en vigor de la presente ley.»

Esta acción, que queda limitada a un periodo de cinco años desde la entrada en vigor del nuevo Código, tiene como mayores beneficiarios los hijos de los marroquíes unidos por vínculos matrimoniales fuera de Marruecos o de los que no pudieron obtener la convalidación del acta matrimonial expedida en el país de residencia.» 
Túnez han sido una referencia para otros países sobre todo aquellos, Marruecos incluido, seguidores de la escuela maliki ${ }^{15}$, que entiende que el hijo concebido antes de la celebración del contrato matrimonial, y por tanto previo al matrimonio válido es atribuido, mediante presunción automática, al marido.

De todos modos, no deja de ser una presunción iuris tantum excepto para la escuela hanafí que la eleva a presunción iuris et de iure.

En cuanto a la filiación materna el nuevo Código de familia marroquí recoge el reconocimiento materno como vía legal para su establecimiento y con idénticos efectos ${ }^{16}$ tanto para hijos legítimos como ilegítimos, a diferencia de lo que ocurre con el padre tal como ha quedado aclarado.

b) La filiación por reconocimiento o Iqrar

Dispone el artículo 160 del Código de la Familia marroquí que:

«La filiación paterna se establece por el reconocimiento del padre que reconoce su paternidad, incluso estando enfermo y en la fase terminal de su vida, de conformidad con las siguientes condiciones:

1. El padre confirmante debe estar en pleno uso de sus facultades mentales;

2. Solo cabe este reconocimiento si no concurre otra filiación ya conocida;

3. Las declaraciones del autor del reconocimiento de la paternidad no deben ser ilógicas o inverosímiles;

4. El niño reconocido debe prestar su consentimiento, si es mayor de edad, en el momento del reconocimiento de la paternidad. Si este reconocimiento se produjo antes de la mayoría de edad, el niño reconocido tiene derecho, cuando alcance dicha mayoría, a accionar un procedimiento judicial de impugnación de la filiación paterna.

Cuando aquel que reconoce la paternidad designa a la madre del hijo, ésta puede oponerse negando ser la madre o aportando las pruebas que acrediten la falta de veracidad del reconocimiento de la paternidad.

Toda persona interesada puede interponer un recurso contra la veracidad de la concurrencia de las condiciones del reconocimiento de la paternidad (Istilhaq) antes citadas, siempre que el autor de este reconocimiento esté en vida.»

15 En referencia al Imam Malik, fundador de una de las cuatro escuelas suníes de exégesis y de interpretación de las normas islámicas. Las tres restantes son: la hanafíe (Imam Abu Hanifa), la Sahfií (Imam al Shafî) y la Hanbalí (Imam Abu Hanbal).

16 Según el artículo 146 del CFM: «La filiación materna producirá los mismos efectos, sea resultado de una relación legítima o ilegítima». 
Es la única alternativa que permite al padre ${ }^{17}$ establecer la filiación legítima del hijo. Se precisa para ello que el reconocimiento se manifieste a través de un certificado auténtico o, en su caso, por un documento ológrafo del declarante ${ }^{18}$.

El acto jurídico por el que se reconoce la paternidad afecta a derechos de terceros y en particular a los del hijo. Las fórmulas de reconocimiento han de ser inequívocas, no pudiendo aludir al carácter ilícito de la relación entre los progenitores, y exigiéndose también una diferencia de edad mínima entre el padre y el hijo. Además, en evitación del fraude, se precisa la ausencia de circunstancias que pongan en duda la veracidad de la declaración o que la hagan inverosímil.

A mi humilde modo de entender, condicionar el reconocimiento de la paternidad al reconocimiento voluntario del padre dejaría la puerta abierta al fraude y a la posibilidad de esquivar las responsabilidades paternas, obligando la mujer a cargar sola con todo ello y privando, es lo peor, al niño del derecho a una identidad conocida ${ }^{19}$. Por lo que, una vez acreditado que la iniciativa del ayuntamiento ilícito haya partido de ambos progenitores, sería contra ambos que debería dirigirse el peso de la responsabilidad y no sólo contra la madre y en detrimento, es lo injustificable, del niño que involuntariamente resulta de este acto, y de ahí evitar que, como consecuencia de su falta, ninguno de ellos caiga en la miseria y sea condenado al sufrimiento ${ }^{20}$.

\section{c) El error o la Shubba}

Un supuesto poco común viene recogido en el artículo 155 del Código de Familia marroquí. En su virtud se reconoce la legitimidad de la filiación, y por ende sus efectos jurídicos, cuando la relación sexual mantenida por los progenitores hubiera sido consumada por mero error. En este supuesto, el error se configura como causa de exención de responsabilidad penal.

d) Legitimación del niño nacido de relaciones de noviazgo

El artículo $156 \mathrm{CF}^{21}$ contempla la posibilidad de la intervención judicial para legitimar al hijo engendrado en las relaciones de noviazgo formal. El precepto requiere que el compromiso ante las dos familias haya sido público, que

17 En virtud del artículo 161 del CFM: «Únicamente el padre puede establecer la filiación de un hijo por reconocimiento de la paternidad, con exclusión de cualquier otra persona».

18 A tenor del artículo 162 del CFM: «El reconocimiento de la paternidad se realiza en documento público o por declaración manuscrita e inequívoca del autor de dicho reconocimiento.»

19 Vid. Anton MENGUER.»El Derecho Civil y los Pobres». Op. cit. pág. 191.

20 Vid. Anton MENGUER.»El Derecho Civil y los Pobres». Op. cit. pág. 194.

${ }^{21}$ Según el artículo 156 del CFM que: «Si tuvo lugar la promesa de matrimonio y con el consentimiento del mutuo, pero circunstancias imperiosas impidieron elaborar el acta matrimo- 
el wali o tutor, en su caso, lo haya consentido, que, además, se aprecie que el embarazo se produjo durante el periodo de noviazgo, y que los novios se autoatribuyan la filiación.

Se desprende de la regulación de esta eventualidad que uno de los presupuestos de reconocimiento de la paternidad es el conocimiento de las familias y su aprobación. A este respecto, consideramos que una promesa de matrimonio debería surtir los mismos efectos, con independencia del conocimiento y consentimiento de la familia, sobre todo cuando sabemos que, en virtud de la nueva reforma, la joven mayor de edad no requiere de la aprobación del tutor para contraer matrimonio, pues sería plenamente válido con su mero consentimiento. Por tanto carece de sentido, a la luz de esta reforma, supeditar la legitimación del niño a condiciones ajenas a la voluntad de la madre, ya que entablar relación con los padres es lo último que haría un embaucador con intenciones claras de engañar ${ }^{22}$. Ésta, probablemente, ha sido engañada por su prometido, y al quedarse embarazada se ve doblemente penalizada. En primer lugar, por verse rechazada por su seductor fraudulento ${ }^{23}$ responsable del embarazo, y, en segundo lugar, debido a que su hijo queda privado del reconocimiento de la paternidad con lo que ello entraña de responsabilidades que recaen en exclusividad sobre ella. Sostenemos, pues, con SALVIOLI que «no constituye homenaje a la igualdad castigar a la mujer y absolver de toda responsabilidad al hombre...; y es también inmoral este absentismo de la ley en orden al padre que desconoce sus deberes y se sustrae a las consecuencias de su maldad» ${ }^{24}$.

\section{DE LOS DERECHOS DE LOS HIJOS}

La filiación (nasab) se inicia desde el momento en que el varón tiene conocimiento del embarazo de la mujer, presumiéndose que la concepción es fruto de

nial y aparecieron señales de embarazo de la novia, este embarazo se imputa al novio por relaciones sexuales por error (shubhs) si se cumplen las siguientes condiciones:

a) si el periodo de esponsales es conocido por las dos familias y aprobado — en su caso— por el tutor matrimonial de la novia;

b) si resulta que la novia está embarazada durante el período de esponsales;

c) si los dos novios reconocieron que el hijo del que está embarazada la mujer es de ambos.

Estas condiciones se establecen por decisión judicial no susceptible de recurso.

Si el novio niega ser el padre del hijo del que se encuentra embarazada la novia, puede recurrir a todos los medios legales de prueba para establecer la filiación paterna.»

22 Cfr. Anton MENGUER. «El Derecho Civil y los Pobres». Op. cit. pág. 194.

${ }^{23}$ Cfr. GIUSEPPE SALVIOLI. «E Derecho Civil y El Proletariado», op. cit. pág. 96.

${ }^{24}$ Cfr. GIUSEPPE SALVIOLI. «E Derecho Civil y El Proletariado», op. cit. pág. 20. 
las relaciones conyugales habidas dentro del matrimonio legítimo. El hombre asume desde entonces las obligaciones de cuidar y mantener a la esposa, que, indirectamente, redundan en beneficio del nasciturus.

En este sentido, el Derecho marroquí prevé que, constante matrimonio, la guarda del niño forma parte de las obligaciones de ambos progenitores pero, una vez disuelto, se confía con carácter prioritario a la madre y después al padre y a la parentela materna y paterna de conformidad con ciertas reglas establecidas.

Si en virtud del texto coránico, base de la regulación marroquí en este extremo, la responsabilidad de alimentar al niño recae sobre la madre desde el momento de su nacimiento, el Código de Familia en Marruecos prevé que la mujer puede reclamar una remuneración distinta a la de la nafaqa o manutención ${ }^{25}$. Ésta se prolonga hasta que los hijos alcancen la mayoría de edad o, en su caso, hasta que finalicen sus estudios, a condición de no sobrepasar los veinticinco años. En caso de las hijas, la obligación persiste mientras no dispongan de recursos propios. De igual modo se mantiene el derecho de manutención de los hijos impedidos o incapaces de mantenerse con independencia de su edad.

Dentro de este conjunto de deberes se engloba la obligación del padre de proporcionar a sus hijos un domicilio y de sufragar los gastos de ello derivados en caso de que la guarda le corresponda a un tercero ${ }^{26}$.

En lo que se refiere a los hijos nacidos de relación sexual ilícita o extramarital, el Derecho marroquí, al reconocer únicamente el favor legitimatis, y por ello negar la atribución de efectos jurídicos frente al progenitor masculino y a los parientes de éste, desatiende los derechos de esta categoría social, dándose el caso de un inconstitucionalidad sobrevenida, tras la entrada en vigor de la

25 Dispone el artículo 189 del CFM que: «La manutención incluye los alimentos, el vestido, los cuidados médicos, la instrucción de los hijos y todo lo que habitualmente se considere indispensable, salvo lo dispuesto en el artículo 168 (arriba).

Para determinar la cuantía de las cargas inherentes a las necesidades antes citadas se tendrá en cuenta, por referencia a la media de las rentas de la persona obligada a abonar la manutención y de la situación del acreedor; el coste de la vida y los usos y costumbres del lugar en el que vive la persona que tiene derecho a la manutención.»

26 A tenor del artículo 168 CFM: «Los gastos de alojamiento del hijo sometido a la hadana se consideran, en su evaluación, independientes de la manutención, la retribución de la hadana y otros gastos.

El padre deberá preparar un alojamiento para sus hijos o pagar la cantidad que el Tribunal considere necesaria para su alquiler; teniendo en cuenta lo dispuesto en el art. 191 (siguiente).

El hijo protegido mediante la hadana no será desalojado del domicilio conyugal hasta que el padre cumpla la sentencia relativa al domicilio del menor sometido a la hadana.

El Tribunal deberá fijar en la sentencia las medidas idóneas para garantizar el cumplimiento de dicha sentencia por el padre condenado.» 
nueva Constitución, por clara infracción del principio de igualdad proclamado en dicha norma, tanto en su faceta formal como material, entre otros ${ }^{27}$, en su artículo 6. Éste dispone que «la ley es la expresión suprema de la voluntad de la nación. Todos, personas físicas o morales, incluidos los poderes públicos, son iguales ante la ley y deben someterse a la misma. Los poderes públicos dirigirán su acción a la creación de las condiciones que permitan generalizar la efectividad de la libertad y de la igualdad de las ciudadanas y ciudadanos, así su participación en la vida política, económica, cultural y social».

Recordemos que el principio de igualdad ante la ley es una vieja aspiración del ser humano que fue recogida por el movimiento constitucional del siglo XVIII que marcó el fin del Antiguo Régimen. Se convirtió, por ello, en una de las principales reivindicaciones de los revolucionarios liberales ${ }^{28}$, especialmente de los franceses ${ }^{29}$, hasta el punto de que su proclamación forma parte de la divisa del Estado surgido de la Revolución Francesa («Libertad, igualdad, fraternidad»).

Se trata de un derecho que, aunque tiene entidad propia, siempre se presenta acompañado de otro. Es un derecho general que se proyecta necesariamente en los distintos tipos de relaciones jurídicas; es, en suma, un derecho y un principio general a la vez ${ }^{30}$.

El análisis de los pronunciamientos judiciales respecto del principio de igualdad destaca el establecimiento de ciertos criterios que permiten distinguir entre una diferencia de trato justificada y otra discriminatoria y, por tanto, constitucionalmente inadmisible (desigualdad de los supuestos de

27 Por ejemplo el artículo 34 de la Constitución en vigor dispone que: «Los poderes públicos elaboran y ponen en marcha política destinadas a las personas y a las categorías sociales con necesidades específicas. A este efecto, velan sobre todo a:

- Tratar y prevenir la vulnerabilidad de ciertas categorías de mujeres y madres, niños y personas de edad,

- Rehabilitar e integrar en la vida social y civil a los minusválidos físicos, sensoriales y mentales y facilitar su disfrute de los derechos y libertades reconocidos a todos.

${ }^{28}$ Vid. A. SERRANO GONZÁLEZ: «El principio de igualdad ante la ley en la jurisprudencia del Tribunal Constitucional», en L. MARTÍN RETORTILLO (ed.): De la jurisprudencia del Tribunal Constitucional, Zaragoza, Seminario de Profesores de la Facultad de Derecho, 1985, pág. 39.

${ }^{29}$ La formulación clásica de la «igualdad ante la ley» es originaria de la Revolución francesa. Así, el artículo 6.» de la Declaración de 1789 dice: «La Ley debe ser la misma para todos, tanto si protege como si castiga», y la Carta otorgada de 8 de junio de 1814 establece que «los franceses son iguales ante la ley».

${ }^{30}$ Cfr. LUIS GÁLVEZ MUÑOZ. La cláusula general de igualdad. Anales de Derecho. Universidad de Murcia. Número 21. 2003. Págs.195-206. Pág. 195. 
hecho; finalidad constitucionalmente legítima; congruencia entre el trato desigual, el supuesto de hecho que lo justifica y la finalidad que se persigue; y proporcionalidad entre los elementos anteriores). Así mismo, subraya dicha jurisprudencia que todo trato desigual basado en ciertas circunstancias personales debe ser sometido a un examen especialmente riguroso, exigiendo un plus de fundamentación de su objetividad y razonabilidad para pasar el test de constitucionalidad $^{31}$.

Ello significa que, salvo justificación razonable y objetivamente verificable, no debe haber estatutos jurídicos diferenciados con base en condiciones perso-

31 A este respecto apunta el TC español en la STC 2001/200, FJ 4 a):

«Como tiene declarado este Tribunal desde la STC 22/1981, de 2 de julio, recogiendo al respecto la doctrina del Tribunal Europeo de Derecho Humanos en relación con el art. 14 CEDH, el principio de igualdad no implica en todos los casos un tratamiento legal igual con abstracción de cualquier elemento diferenciador de relevancia jurídica, de manera que no toda desigualdad de trato normativo respecto a la regulación de una determinada materia supone una infracción del mandato contenido en el art. $14 \mathrm{CE}$, sino tan sólo las que introduzcan una diferencia entre situaciones que puedan considerarse iguales, sin que se ofrezca y posea una justificación objetiva y razonable para ello, pues, como regla general, el principio de igualdad exige que a iguales supuestos de hecho se apliquen iguales consecuencias jurídicas y, en consecuencia, veda la utilización de elementos de diferenciación que quepa calificar de arbitrarios o carentes de una justificación razonable. Lo que prohíbe el principio de igualdad son, en suma, las desigualdades que resulten artificiosas o injustificadas por no venir fundadas en criterios objetivos y razonables, según criterios o juicios de valor generalmente aceptados. También es necesario, para que sea constitucionalmente lícita la diferencia de trato, que las consecuencias jurídicas que se deriven de tal distinción sean proporcionadas a la finalidad perseguida, de suerte que se eviten resultados excesivamente gravosos o desmedidos. En resumen, el principio de igualdad, no sólo exige que la diferencia de trato resulte objetivamente justificada, sino también que supere un juicio de proporcionalidad en sede constitucional sobre la relación existente entre la medida adoptada, el resultado producido y la finalidad pretendida (SSTC 22/1981, de 2 de julio, FJ 3; 49/1982, de 14 de julio, FJ 2; 2/1983, de 24 de enero, FJ 4; 23/1984, de 20 de febrero, FJ 6; 209/1987, de 22 de diciembre, FJ 3; 209/1988, de 10 de noviembre, FJ 6; 20/1991, de 31 de enero, FJ 2; 110/1993, de 25 de marzo, FJ 6; 176/1993, de 27 de mayo, FJ 2; 340/1993, de 16 de noviembre, FJ 4; 117/1998, de 2 de junio, FJ 8, por todas).» Y añade que «No obstante este Tribunal ha admitido también que los motivos de discriminación que dicho precepto constitucional prohíbe puedan ser utilizados excepcionalmente como criterio de diferenciación jurídica (en relación con el sexo, entre otras, SSTC 103/1983, de 22 de noviembre, FJ 6; 128/1987, de 26 de julio, FJ 7; 229/1992, de 14 de diciembre, FJ 2; 126/1997, de 3 de julio, FJ 8; en relación con las condiciones personales o sociales, SSTC 92/1991, de 6 de mayo, FF JJ 2 a 4; 90/1995, de 8 de julio, FJ 4; en relación con la edad, STC 75/1983, de 3 de agosto, FF JJ 6 y 7; en relación con la raza, STC 13/2001, de 29 de enero, FJ 8), si bien en tales supuestos el canon de control, al enjuiciar la legitimidad de la diferencia y las exigencias de proporcionalidad resulta mucho más estricto, así como más rigurosa la carga de acreditar el carácter justificado de la diferenciación.» 
nales ${ }^{32}$, por lo que el nacimiento fuera del matrimonio es una circunstancia que jamás debe ser tenida en cuenta ${ }^{33}$. El legislador marroquí pasó por alto estos criterios comúnmente aplicados en el derecho comparado al excluir del alcance de la regulación de la filiación a los hijos adulterinos.

\section{DE LA PATERNIDAD}

En primer lugar cabe resaltar que, en caso de divorcio, una de las medidas articuladas por el legislador marroquí para impedir la posible denegación de paternidad es la supresión de la práctica del niño dormido ${ }^{34}$ a cuyo tenor se concebía un período de gestación que podía alargarse a los tres años.

El Derecho islámico distingue entre dos clases de hijos ilegítimos. La primera corresponde al hijo negado por el juramento de anatema o «Al li an», y la segunda hace referencia al hijo fruto de relaciones extramatrimoniales. En ambos casos se les niegan los lazos de parentesco respecto de la familia paterna en general y del padre en particular.

Los efectos inmediatos de la negación de paternidad, cabe apuntarlo, no mencionados en el Corán, son la privación del derecho a heredar, la negación del derecho a su mantenimiento y la no aplicación de los impedimentos de matrimonio $^{35}$. Sin embargo, el hijo no reconocido como legítimo heredará de su madre y de todos los parientes de ella, de sus hermanos y hermanas uterinas, equiparándose en este caso al hijo legítimo debido a que la filiación materna no resulta controvertida.

32 Véase a este respecto, ENRIQUE ÁLVAREZ CONDE. Prohibición de la discriminación. In «Estudios Interdisciplinares sobre Igualdad», 2009, págs. 39-54.

33 Cfr. Luis Martínez-Calcerrada y Gómez. Análisis de la sentencia del Tribunal Constitucional de 20 de diciembre de 1982 sobre reconocimiento de filiación extramatrimonial. La Ley: Revista jurídica española de doctrina, jurisprudencia y bibliografía, n. ${ }^{\circ} 3,1983$, págs. 1029-1037.

34 El Código marroquí aborda esta cuestión en su última reforma. En relación al término del embarazo regula el periodo de 'idda (o abstinencia de matrimonio) de la mujer embarazada, a efectos de la disolución del matrimonio, y al objeto de evitar la negación de paternidad por parte del marido. Según dicha reforma la mujer se someterá a la opinión de expertos para determinar si se encuentra embarazada, y de este modo fijar el plazo máximo de su gestación, que en todo caso será de un año, y se efectuará con la mayor precisión posible a fin de evitar cualquier interpretación errónea que pudiera perjudicarle a ella y al futuro hijo.

35 Véase párrafo correspondiente a la filiación e impedimentos del matrimonio. 
La denegación imprecatoria de paternidad formalizada a través del juramento de anatema ${ }^{36}$ o $l i^{\prime} A n^{37}$, en cuya virtud el marido alega que el niño no resulta de una relación sexual mantenida con la esposa, se pronuncia ante el juez, quien decreta la separación de los cónyuges, tratándose de una anulación con carácter irrevocable no considerada como divorcio. Al esposo se le reconoce la posibilidad de desvirtuar la presunción de paternidad según la pauta coránica establecida consistente en jurar cuatro veces su veracidad y de imprecar, acto seguido, el castigo divino sobre sí si su acusación es falsa, requiriéndose el testimonio de cuatro testigos que apoyan su pretensión acusando de adulterio a su mujer. La mujer puede defenderse con juramento análogo, o puede apoyarse en una prueba de ADN, siempre y cuando sea ordenada judicialmente, y en consecuencia se anulan ambos juramentos. Pero de todos modos se entiende desvirtuada la presunción de paternidad, y denegados los derechos derivados de la misma. Ello se debe a que, como venimos subrayando, la filiación viene determinada, principalmente, por la voluntad del padre.

\section{DE LA PRUEBA DE ADN, DE LA FILIACIÓN, ADOPCIÓN E IMPEDIMENTOS DEL MATRIMONIO}

\subsection{De la prueba de $A D N$}

Es sabido que la prueba es el medio que permite al juzgador tener el pleno convencimiento sobre la verdad o falsedad de los hechos aducidos por las partes en defensa de sus pretensiones.

36 Dispone el artículo 153 del CFM que: «Las relaciones conyugales se prueban por los mismos medios que el matrimonio.

Las relaciones conyugales, que cumplen sus requisitos, constituyen una prueba irrefutable para el establecimiento de la filiación paterna. Sólo podrán ser contestadas por el marido según el juramento de Anatema (Liâane) o por medio de prueba pericial a condición de que:

— el esposo concernido presente pruebas sólidas en apoyo de sus alegaciones; y

- que la referida pericia sea ordenada judicialmente.»

${ }^{37}$ Lo que en puridad expresa «Al li'an» es una crisis de confianza, base de la unión conyugal en virtud del texto coránico («Ellas son un vestido para vosotros y vosotros sois un vestido para ellas». Aleya n. ${ }^{\circ}$ 187. Sura de la vaca: Traducción-Comentario del noble Corán. Darussalam. Editores y distribuidores. P.O. BOX 22743, Riyadh 11416. RIYADH - HOUSTON - LAHORE.), pero que de ningún modo debe afectar la filiación biológica, máxime cuando dicho lazo puede corroborarse por una prueba de ADN cuya fiabilidad es reconocida. Por ello, la paternidad debe atribuirse al progenitor biológico y sus efectos deben desplegarse en toda su plenitud, salvaguardando así el derecho del hijo a su verdadera identidad y asegurando sus derechos. 
La determinación de la paternidad es una práctica tan vieja como el Derecho mismo. Las presunciones previstas en el Derecho romano son claro ejemplo de ello. Éstas persisten hasta nuestros días siendo en muchos casos el único medio previsto para establecer la verdad judicial, que en no pocos casos difiere de la verdad social. No obstante, hoy por hoy, este anacrónico sistema de presunciones va cediendo el lugar de privilegio que venía ocupando a favor de las pruebas biológicas en varios tipos de procesos. El Derecho Norteamericano se refiere a esta cuestión con la expresión gráfica de que «la ciencia sube al estrado». En lo que a nosotros nos interesa, el test de ADN es claro ejemplo de ello en lo que a la determinación de la paternidad se refiere.

A mi entender, permitir la investigación de la paternidad supone elevar a la categoría de bien jurídico supremo al interés del hijo y de ahí, no sólo la posibilidad, sino la obligatoriedad de establecer su filiación biológica. En contra de los ordenamientos donde el interés del hijo opera como criterio disolvente de la otrora distinción entre filiaciones ${ }^{38}$, en el derecho marroquí rige una concepción formal de la filiación debido a la prohibición de la investigación de la paternidad fuera de los supuestos legales contemplados en el artículo 159 del Código de familia, lo que obliga a mantener la filiación jurídica constituida en detrimento de la verdad biológica, incluso aportando la prueba de ADN que niega la paternidad establecida ${ }^{39}$.

De este modo, el hijo ilegítimo no tiene derecho a la reclamación de la paternidad biológica tal como dispone el artículo 148 del Código de familia:

38 El Tribunal Supremo en sentencia de 5 de noviembre de 1987 (RJ 1987, 8336) resalta el rango constitucional del derecho a investigar la paternidad en cuanto se estima más protegible el interés del menor, la realidad a la ficción formal.

Por su parte la sentencia del Tribunal Superior de Justicia de Cataluña de 27 de octubre de 2003 (AC 2003, 8211) pone de manifiesto la decidida decantación del Tribunal Supremo en el marco de la tensión formalismo-realismo en materia de filiación hasta el principio de veracidad, a través de una interpretación sociológica y finalista de las principales normas implicadas con una clara preferencia por la verdad real, dado que en este sentido converge casi siempre el interés del menor.

39 El uso restringido de las pruebas de ADN sigue dependiendo de la voluntad de los jueces que se muestran reacios a admitir para todo tipo de casos dicha prueba. En esta línea, la resolución del TS n $\mathrm{n}^{\circ} .658$ de 30 de diciembre de 2004 consagra la tendencia jurisprudencial de priorizar la filiación jurídica en detrimento de la biológica. En esta sentencia brilla el carácter irrefutable de la presunción de la paternidad legítima, obviándose la prueba de ADN realizada en Francia, que establecía la no paternidad del marido de la madre. El TS sigue dando valor primordial a los plazos establecidos en la ley para seguir apoyando la paternidad legítima establecida, frente a los nuevos resultados de la prueba biológica. la paternidad atribuida de todo hijo nacido de mujer casada, aun en situaciones inverosímiles, y pese a lo expuesto en la legislación vigente, es la tendencia actual seguida por las autoridades judiciales marroquíes. 
«la filiación ilegítima no surtirá ninguno de los efectos de la legítima frente al padre». A tenor de este artículo y de la práctica jurisprudencial ${ }^{40}$ reina la postergación de la verdad biológica como criterio para la determinación de la filiación, ya que se le niega a la madre la posibilidad de presentar como medio probatorio el resultado de una prueba de $\mathrm{ADN}$, lo que da lugar a que existan progenitores biológicos no reconocidos formalmente como padres y padres jurídicos y que no son los ascendientes biológicos.

Escapa al legislador timorato que el hijo fruto de esta relación no deja de ser inocente y víctima, tal como ocurre con los niños nacidos de una matrimonio nulo que, paradójicamente, genera efectos jurídicos. Inocente por cuanto la comisión del acto censurado, religiosa y legalmente, sólo puede ser atribuida a los progenitores, y víctima en cuanto se le priva de los efectos de la paternidad y se exime al padre de las obligaciones que derivan de su paternidad biológica.

Estimo, a estas alturas, conveniente dejar claro que al quedar asegurada, en los supuestos previstos en los artículos 16 y 156 del CF, la relación paternofilial con las pruebas de ADN se debería reconsiderar la concepción formalista imperante. Revisión consecuente por cuanto la legitimidad de la filiación según los referidos artículos no deriva de la legitimidad de las relaciones sexuales.

No resulta ocioso insistir en que el niño nacido de unas relaciones sexuales ilícitas se vincula a la madre. Se heredan entre ellos, pero los derechos sucesorios respecto del padre biológico no se reconocen alegando una interpretación literal, y de ahí incompleta, del relato profético ${ }^{41}$ cuyos términos disponen que el niño adulterino se atribuye a la cama (de ahí la presunción al firach). La literalidad del texto lleva al absurdo por cuanto nadie desciende de un lecho sino de los que lo compartieron para concebirlo, por lo que la atribución al lecho sólo

${ }^{40} \mathrm{La}$ fuerte presunción al firach (el lecho) se presenta en la resolución del TS marroquí de 4 de enero de 2004, que declara al hijo matrimonial al producirse el nacimiento después de los seis meses de la celebración del matrimonio, incluso demostrándose que la esposa fue adúltera mediante sentencia penal condenatoria.

En la STS marroquí n 84 de 16 de febrero de 1999, «Revue de Jurisprudence de la Cour Suprême», $\mathrm{n}^{\circ}$. 61, pp 72-74 en árabe: el esposo niega la paternidad y el pago de alimentos, ya que no se consumó el matrimonio al repudiar el marido a la esposa. Sin embargo, la corte suprema considera que no hace falta la prueba de las relaciones sexuales de los progenitores, pues la filiación legítima se produce con sólo haber nacido después de los seis meses de celebración del matrimonio entre los progenitores.

La resolución del TS marroquí de 7 de septiembre de 2000, Revue de Jurisprudence de la Cour Suprême, $\mathrm{n}^{\circ}$. 61, pp 77-80, también declara la filiación legítima del nacido después de los seis meses del matrimonio de sus progenitores, aunque el marido pruebe que es estéril.

41 «Al walado lil firach» que podría traducirse en los siguientes términos: «El hijo se imputa al lecho». 
responde a la duda sobre la identidad del padre a quién se imputa el hijo en el derecho islámico ${ }^{42}$.

Llevar esta interpretación literal a sus últimas consecuencias lleva derechamente a privarlo de los derechos sucesorios respecto tanto del padre como de la madre. Sin embargo, como queda claramente expuesto, se le reconocen al niño sus derechos con relación a la madre debido a que al embarazo y el parto son evidencias incontestables de la maternidad. Se trata, por tanto, de meras cuestiones probatorias. $\mathrm{Y}$ ies que puede sacrificarse un derecho porque su prueba resulte difícil? ${ }^{43}$ Desde luego que con el resultado de una prueba de ADN desaparece la justificación y se disipa el temor.

A tenor del referido relato, y de acuerdo con la doctrina, prudente en este sentido, al establecer (el recurso a la versión árabe resulta esclarecedor) que $e l$ bijo de adulterio (atribuyendo el hijo al acto), y no el hijo del adultero o de la adultera, no hereda, se entiende que no se le reconocen los derechos sucesorios a aquél cuya filiación resulte indeterminada como es el caso de los hijos abandonados o cuya filiación no haya podido determinarse, y no porque sea fruto de un ayuntamiento ilícito, ya que la ilicitud alcanza a la madre también en cuanto parte de la relación sexual prohibida, y sin embargo se heredan entre ellos. De cuando antecede se puede colegir sin titubeo que la filiación no se niega por razón de la ilicitud de la relación sexual sino debido a las dudas respecto a su atribución.

Una relación ilícita, pues, a la luz del artículo 147 del Código de Familia Marroquí que dispone que la filiación respecto de la madre se establece por el hecho del nacimiento, no conlleva la negación de la filiación. El mismo razonamiento debe aplicarse a la filiación respecto del padre, con independencia del reconocimiento (iqrar) exigido por la misma norma, siendo suficiente en este supuesto una prueba pericial que, hoy por hoy, puede ser un análisis de su ADN. Su resultado debería despejar toda sombra de duda sobre la otra parte en la concepción del niño y la atribución fundada de la filiación con sus obligaciones inherentes.

Si no se puede sostener que la actitud del legislador marroquí comulgue con la del legislador francés del siglo XIX, tampoco se puede defender que la restricción de la investigación de la paternidad, recogida anteriormente en el Código Galo, responda al deseo de preservar la familia legítima, sino que podría responder a la conservación de la paz familiar (elevada a la categoría de bien

${ }^{42}$ Dijo el profeta que «el hijo a su padre» lo que significa que se imputa al progenitor masculino.

43 Vid. Antón MENGUER. «El Derecho Civil y los Pobres». Op. cit. Pág. 199. 
jurídico) en algunos casos, y al uso de un único criterio interpretativo, y de ahí incompleto, de la referencia textual en otros casos.

Para combatir los abusos que se pueden dar debido a esta prohibición, nada más valioso que la investigación de la paternidad para ajustar la realidad registral a la nueva situación y la equiparación de los derechos de los niños nacidos de uniones extramatrimoniales a los que resultan de un matrimonio legítimo, y de ahí el establecimiento de los deberes hacia la prole al apellido y los demás derechos tanto frente al padre como a la madre.

Más aún, al ser la paternidad un derecho del niño debe promoverse su reconocimiento tanto por los progenitores como por el Ministerio Público, máxime cuando la filiación resulte de una violación. Es una cuestión de orden público por cuanto afecta al establecimiento de la filiación y, por ello, a los derechos y obligaciones que del modo regulado por el artículo $161^{44}$ estarían anulados. Esta necesidad se ve avalada por la Convención de los Derechos del Niño, ratificada por Marruecos ${ }^{45}$, que en su artículo 8 establece que «1. Los Estados Partes se comprometen a respetar el derecho del niño a preservar su identidad, incluidos la nacionalidad, el nombre y las relaciones familiares de conformidad con la ley sin injerencias ilícitas.» $\mathrm{Y}$ añade que «2. Cuando un niño sea privado ilegalmente de algunos de los elementos de su identidad o de todos ellos, los Estados Partes deberán prestar la asistencia y protección apropiadas con miras a restablecer rápidamente su identidad».

Conviene puntualizar que, a pesar de que las Declaraciones islámicas, sólo reconocen a la familia matrimonial bajo la afirmación de que «el matrimonio es el medio legítimo establecido por la ley islámica para fundar una familia, tener descendencia y permanecer personalmente casto ${ }^{46}$, nada dicen, sin embargo, respecto del hijo nacido de relaciones extramatrimoniales, por lo que resultaría osado sacar conclusiones al respecto, máxime cuando están en juego los intereses de una categoría social inerme.

Por último quisiera apuntar que si el Derecho Islámico prohíbe que ante cualquier juez, a instancia del hijo, de su representante o de otra persona con interés legítimo, se inste la declaración judicial de la filiación e inicie el procedimiento de investigación de la paternidad, es porque la relación extramatrimonial acarrea la aplicación de la pena capital, por lo que se deja entrever que con esta prohibición, manifiestamente ponderada, se pretende proteger la vida

44 Sólo el padre puede determinar la filiación de un hijo por reconocimiento de la paternidad, con exclusión de cualquier otra persona.

${ }^{45}$ Dahir n. ${ }^{\circ}$ 1-93-363, de 21 de noviembre de 1996. B.O. n. ${ }^{\circ} 4440$, de 19 de diciembre de 1996.

46 Artículo 19 de la Declaración Islámica Universal de los Derechos del Hombre. 
del infractor. Pero debido a que el Código penal marroquí en su artículo $491^{47}$ establece una pena de entidad mucho menor, en términos comparativos, no se debe sacrificar la verdadera paternidad en aras de proteger un bien menor.

Dicho esto, y llevando el análisis al terreno de los derechos fundamentales ${ }^{48}$ podría plantearse la posible vulneración de ciertos derechos del progenitor masculino al imponerse la prueba de ADN. Sin embargo, un mero repaso de la doctrina establecida sobre la materia dejaría resuelta esta cuestión.

En lo referido a un posible ataque a la dignidad del progenitor paterno, la jurisprudencia internacional sobre la materia considera que las intervenciones corporales no atentan contra la dignidad de las personas, siempre y cuando sean respetuosas con determinados presupuestos.

Así mismo, la realización de la prueba de ADN tampoco supone una violación del derecho a la intimidad ${ }^{49}$ puesto que con ella no se revela el mapa genético de la persona sino la huella genética, destinada únicamente a determinar si existe o no una relación de paterno-filial entre el presunto progenitor y su presunto hijo.

En el mismo orden de ideas, la extracción de sangre, necesaria también para la realización del test de $\mathrm{ADN}$, es un procedimiento común en el campo de la medicina a la que se recurre, entre otros, para el desempeño de ciertos trabajos o para la obtención de un visado. De ahí que se pueda afirmar en consonancia con la Comisión Europea de Derechos Humanos ${ }^{50}$, que «una intervención tan banal como un examen de sangre no constituye injerencia prohibida por el artículo 2.1 del Convenio europeo (derecho a la integridad física)».

Para cerrar este apartado conviene recordar que para determinar la constitucionalidad de una restricción a los derechos fundamentales, muchos Tribunales, como es el caso del Tribunal Constitucional español, someten los intereses en conflicto al test de proporcionalidad para calibrar la proporcionalidad o no de

47 Dispone el artículo 491 del Código penal marroquí que «Est puni de l'emprisonnement d'un à deux ans toute personne mariée convaincue d'adultère. La poursuite n'est exercée que sur plainte du conjoint offensé.

Toutefois, lorsque l'un des époux est éloigné du territoire du Royaume, l'autre époux qui, de notoriété publique, entretient des relations adultères, peut être poursuivi d'office à la diligence du ministère public.»

48 Cfr. Victoria Iturralde Sesma. Cuadernos constitucionales de la Cátedra Fadrique Furió Ceriol, No 20-21, 1997, págs. 181- 214.

49 Cfr. Ana María DELGADO CORDERO. Negativa al sometimiento de las pruebas biológicas para la investigación de la paternidad: futa confessio. Perspectivas del derecho de familia en el siglo XXI: XIII Congreso Internacional de Derecho de Familia / coord. por Carlos Lasarte Alvarez, Araceli Donado Vara, María Fernanda Moretón Sanz, Fátima Yáñez Vivero, 2004.

${ }^{50}$ Decisión 8278, de 13 de octubre de 1979. 
los sacrificios derivados de la limitación de un derecho fundamental ${ }^{51}$ con la finalidad a la que dicha intromisión ha de servir ${ }^{52}$. Dicho principio de proporcionalidad conlleva la aplicación de tres criterios:

En primer lugar, que la restricción sea idónea para a alcanzar el fin legítimo perseguido y, en segundo lugar, que sea necesaria o imprescindible para lograr dicho fin y, por último, que el sacrificio a realizar en aras de alcanzar dicho fin, no sea desmedido en comparación con la gravedad de los hechos.

Aplicados estos criterios, comunes en la jurisprudencia de la mayoría de los Estados de Derecho, concluimos que la prueba de ADN es un medio idónea para comprobar la relación paterno-filial. Además, resulta imprescindible para determinar con certeza la identidad del hijo, y no supone un grave menoscabo ni a la libertad ni a la integridad personal del presunto progenitor.

La prohibición que opera en Marruecos de la citada prueba imposibilita la obtención de una evidencia decisiva por parte de quien insta de buena fe y en defensa de sus derechos el reconocimiento de la filiación. Esta prueba biológica es un elemento probatorio que puede ser decisivo para alcanzar una verdad judicial sustentada en datos reales. Su inadmisión como medio probatorio sólo permite consagrar la impunidad con desconocimiento de las cargas y deberes del progenitor masculino en este caso.

A mayor abundamiento, al permitir la legalización del matrimonio, lo que, en puridad, pretende atinadamente el legislador es asegurar la filiación biológica y hacerla coincidente con la realidad registral, sin embargo lo que no se entiende es por qué razón cambia de objetivo cuando los progenitores no llevan a término su proyecto conyugal.

Aunque no cabe sino valorar positivamente la línea jurisprudencial ${ }^{53}$ que establece una indemnización por daños y perjuicios a favor del nacido de relaciones sexuales ilícitas que demande a su padre biológico por responsabilidad extracontractual, jurisprudencia recogida por la guía del ministerio de justicia en su explicación del artículo 148 del Código de familia marroquí, dicho cauce procesal se nos presenta incompleto por cuanto no permite, desafortunadamente, restablecer la verdadera filiación del hijo y asegurarle la totalidad de sus derechos.

Por último, anotamos que el hecho de que el legislador tenga como finalidad combatir el adulterio imputando a un supuesto de hecho (adulterio)

51 Sentencias 26/1981 y 13/1985 del Tribunal Constitucional español.

52 STC 7/1994.

53 Cfr. Resolución del TS marroquí no 9447, de 13 de noviembre de 1962, RMD, 1963, pág. 267. 
consecuencias jurídicas (privación de derechos de personas resultantes de este hecho y no responsables de la comisión del hecho sancionable) le priva de razonabilidad y objetividad y resulta en desproporción patente con tal fin haciendo, además, que incurra en un voluntarismo arbitrario constitucionalmente reprochable.

\subsection{Filiación, Kafala ${ }^{54}$ e Impedimentos del Matrimonio}

Es harto sabido que la adopción plena no cabe en el Derecho Islámico y de ahí su proscripción en el derecho positivo marroquí, que sólo reconoce la institución de la kafala equiparable a una tutela dativa carente de efectos jurídicos en lo que a la filiación se refiere. Una vez constituida, el «kafil» asume las mismas obligaciones, que tendría respecto de sus hijos, de subvenir a las necesidades del «makful», comprendiendo su alojamiento, manutención y educación hasta cumplir la mayoría de edad, prolongándose en caso de las féminas hasta contraer matrimonio o poder sufragar autónomamente sus propios gastos. Además, en Marruecos, el sistema judicial autoriza el tanzil, o gratificación testamentaria que permite al niño (makful), percibir una parte de la herencia.

La referida proscripción, defiende la necesidad de preservar la verdadera filiación, suponiendo que todo niño por el mero hecho de nacer la tiene, y garantizando, de este modo, la permanencia del lazo natural y su atribución a su progenitor biológico. Pues, a tenor de ello, en línea de principio, según el derecho islámico o el derecho marroquí, en nuestro caso, resulta inconcebible encontrar una persona sin filiación, eso es sin lazos maternos y paternos (sean legítimos o no), de ahí que la filiación sea un derecho personalísimo e irrenunciable y que debe gozar de la máxima protección.

Además de la consideración de la filiación biológica como bien jurídico digno de protección, hay una justificación adicional constantemente alegada, no sin razón, y que consiste en evitar relaciones incestuosas que serían posibilitadas por un cambio de filiación que operaría en caso de una adopción plena.

${ }^{54}$ El artículo 149 del Código de familia dispone que: «La adopción (Attabani) es jurídicamente nula y no produce ninguno de los efectos de la filiación paterna legítima.

La adopción de gratificación (Jaza) o de asimilación al rango de hijo (Tanzil), en virtud de la cual una persona se coloca en el rango del primer heredero, no estable la filiación y se regirá por la normativa reguladora del testamento (Wasiya)». Ley 15-01 promulgada por dahir el 13 de junio de 2002 (B.O. n. ${ }^{\circ}$ 5036, de 15 septiembre 2002). 
Inferencia inmediata de dicho alegato es que la no atribución de la paternidad, fuera de los supuestos del Código de familia marroquí, no imposibilitaría una eventual relación entre familiares afectados por los impedimentos del matrimonio 55 .

55 Dichos impedimentos, según el Derecho islámico, pueden ser permanentes o temporales.

Son permanentes todos los supuestos de relación de parentesco, al igual que en los ordenamientos jurídicos occidentales, si bien su ámbito es bastante más amplio debido, principalmente, a la poligamia y a la lactancia. Así, se dirime el matrimonio entre parientes consanguíneos, a los que se asimilan los adoptados y los de leche, en cualquier grado de la línea recta y hasta el tercer grado en línea colateral. El impedimento de parentesco por afinidad resulta más complicado por razón de la poligamia.

Como impedimentos temporales pueden señalarse la afinidad temporal, la continencia legal o $i d d a$, el resultante del divorcio triple.

Los efectos de un matrimonio nulo son los siguientes:

1) No impone período de 'idda a la mujer, salvo que se haya consumado el matrimonio.

2) No genera derechos sucesorios entre los cónyuges.

3) No genera relaciones de parentesco con la familia del aparente cónyuge siempre y cuando el matrimonio no se haya consumado.

4) El régimen jurídico que se aplica a la dote variará en función de si se ha consumado o no el matrimonio. De este modo, en caso de haber sido consumado a la mujer le corresponde la dote en su totalidad, mientras que en caso contrario le corresponde la mitad.

Idda: Consiste en la prohibición, que afecta a la mujer, de contraer matrimonio durante determinados plazos.

Los plazos de continencia varían según la causa que motiva la extinción del vinculo: tres meses si es por divorcio bain, (tres formulaciones consecutivas en un solo acto), cuatro meses y diez días si es por fallecimiento del esposo y 1 mes cuando se hayan mantenido relaciones extramatrimoniales o haya sido violada. Se fundamenta en la necesidad de evitar los posibles problemas que para la determinación de la paternidad pueden conllevar los matrimonios consecutivos en el tiempo.

Impedimentos por razón de poligamia: El marido no puede contraer matrimonio con las ascendientes de su mujer en cualquier caso, mientras que con las descendientes lo podrá hacer siempre que no se haya consumado el matrimonio.

Impedimentos por falta de afinidad temporal: Impide estar casado con dos consanguíneas simultáneamente pero si puede hacerlo sucesivamente, una vez disuelto el anterior matrimonio.

Impedimentos por ser hermano de lactancia: implica la prohibición al varón de contraer matrimonio ni con su nodriza, ni con las hijas, hermanas y sobrinas de esta, y tampoco puede estar casado simultáneamente con dos colactáneas. Lo mismo ocurre para la mujer, con la salvedad de que si que puede hacerlo con los descendientes de la nodriza. Y respecto de la nodriza no puede contraer matrimonio con el que amamantó, ni con su padre y descendientes.

Impedimento por razón de divorcio triple: El divorcio triple o irrevocable perfecto impide que la mujer pueda contraer matrimonio de nuevo con el hombre del que se ha divorciado, a menos que habiendo contraído nuevo matrimonio con otro hombre lo haya disuelto. 


\section{REFLEXIONES FINALES}

Tras este repaso hemos podido comprobar el anacronismo en el que incurre el legislador marroquí al sostener un criterio formalista en detrimento la verdad acreditada por medios científicos fidedignos.

Por ello sostenemos con QUESADA GONZÁLEZ ${ }^{56}$ que el derecho a conocer la filiación de origen debe ser elevado a la categoría de derecho de la personalidad, por cuanto presenta íntimas vinculaciones con la persona, con su dignidad y con el libre desarrollo de la personalidad.

A mayor abundamiento, los derechos de alimento y sucesorios de los hijos son cuestiones integrantes de los conceptos de orden público e interés social, prevalentes ante la alegación por parte del progenitor de cualquier derecho individual. Por lo que en los supuestos de filiación debe prevalecer el interés del menor ya que están en juego los referidos derechos de alimentos y sucesorios de los hijos.

En el mismo orden de ideas, afirmamos que ni en España ni en Marruecos, puede encontrarse disposición de rango constitucional alguna que pueda legítimamente fundamentar un trato desigualitario entre hijos nacidos de un matrimonio legítimo y los nacidos a raíz de una relación extramatrimonial.

De hecho la jurisprudencia del Tribunal constitucional español sobre este particular ha sido tajante. Así en su STC 2001-200, afirma el Alto Tribunal que «dentro de la prohibición de discriminación del art. 14 CE y, más concretamente, dentro de la no discriminación por razón del nacimiento, este Tribunal ha encuadrado la igualdad entre las distintas clases o modalidades de filiación (SSTC 7/1994, de 17 de enero, FJ 3.b; 74/1997, de 21 de abril, FJ 4; 67/1998, de 18 de marzo, FJ 5; AATC 22/1992, de 27 de enero; 324/1994, de 28 de noviembre), de modo que deben entenderse absolutamente equiparadas éstas (ATC 22/1992, de 27 de enero). Y directamente conectado con el principio constitucional de no discriminación por razón de filiación (ATC 22/1992, de 27 de enero), se encuentra el mandato constitucional recogido en el art. 39.2 CE, que obliga a los poderes públicos a asegurar «la protección integral de los hijos, iguales éstos ante la Ley con independencia de su filiación» (STC 7/1994, de 17 de enero, FJ 3.b), de manera que toda opción legislativa de protección de los hijos que quebrante por sus contenidos esa unidad, incurre en una discriminación por razón de nacimiento expresamente prohibida por el art. $14 \mathrm{CE}$, ya que la filiación no admite categorías jurídicas intermedias (STC 67/1998, de 18 de marzo, FJ 5).»

56 Cf. QUESADA GONZALEZ M.C., «El derecho (¿constitucional?) a conocer el propio origen biológico», ADC, 1994-1, págs. 277y 278, en especial notas n. ${ }^{\circ} 122$ y 123. 
Lo mismo cabe extraer de la norma marroquí estableciente del principio de igualdad en el artículo 6 de la Constitución enriquecido por el compromiso recogido en el artículo 34 de la misma de tratar de prevenir la vulnerabilidad de ciertas categorías de mujeres y madres, niños y personas de edad. Por ello, bajo ningún concepto puede admitirse que el poder legislativo participe en la creación de estatus discriminatorios que den lugar a la constitucionalmente combatida vulnerabilidad, ya que llegado el caso, y aprovechando el cauce procesal — la excepción de inconstitucionalidad- establecido por la última reforma de la Constitución, el poder judicial en tanto que garante natural de los derechos, debe recurrir ante el Tribunal Constitucional las expuestas disposiciones por vulneración del principio de igualdad, pilar fundamental del Estado de Derecho.

Title:

THE DISCRIMINATORY TREATMENT OF THE EXTRAMARITAL FILIATION IN MOROCCO

\section{Resumen:}

No hay ninguna disposición de rango constitucional que pueda legítimamente fundamentar un trato desigualitario entre hijos nacidos de un matrimonio legítimo y los nacidos a raíz de una relación extramatrimonial. Los derechos de los hijos son cuestiones integrantes de los conceptos de orden público e interés social, prevalentes ante cualquier derecho individual del progenitor.

\section{Abstract:}

There is no disposition of constitutional range that could base legitimately a not egalitarian treatment between born children of a legitimate marriage and born immediately after an extramarital relation. The rights of the children are integral questions of the concepts of public order and social interest, which must prevail before any individual right of the progenitor.

Palabras clave:

Igualdad, Filiación, ADN, Derechos.

Key words:

Equality, Filiation, ADAN, Rights. 